\title{
Application of an Activated Carbon-Based Support for Magnetic Solid Phase Extraction Followed by Spectrophotometric Determination of Tartrazine in Commercial Beverages
}

\author{
José A. Rodríguez, ${ }^{1}$ Karen A. Escamilla-Lara, ${ }^{1}$ Alfredo Guevara-Lara, ${ }^{1}$ \\ Jose M. Miranda, ${ }^{2}$ and Ma. Elena Páez-Hernández ${ }^{1}$ \\ ${ }^{1}$ Laboratorio 2, Área Académica de Química, Universidad Autónoma del Estado de Hidalgo, \\ Carretera Pachuca-Tulancingo Km. 4.5, 42184 Mineral de la Reforma, HGO, Mexico \\ ${ }^{2}$ Departamento de Química Analítica, Nutrición y Bromatología, Facultad de Veterinaria, \\ Universidad de Santiago de Compostela, Pabellón 4 Planta Baja, Campus Universitario, s/n, 27002 Lugo, Spain
}

Correspondence should be addressed to Ma. Elena Páez-Hernández; mpaezh@gmail.com

Received 17 October 2014; Accepted 18 January 2015

Academic Editor: Faezeh Khalilian

Copyright (C) 2015 José A. Rodríguez et al. This is an open access article distributed under the Creative Commons Attribution License, which permits unrestricted use, distribution, and reproduction in any medium, provided the original work is properly cited.

A method is presented for magnetic solid phase extraction of tartrazine from nonalcoholic beverages. The method involves the extraction and clean-up by activated carbon covered with magnetite dispersed in the sample, followed by the magnetic isolation and desorption of the analyte by basified methanol. The tartrazine eluted from the magnetic support was determined by spectrophotometry. Under optimal conditions, the linear range of the calibration curve ranges from 3 to $30 \mathrm{mg} \mathrm{L}^{-1}$, with a limit of detection of $1 \mathrm{mg} \mathrm{L}^{-1}$. The method was validated by comparing the results with those obtained by HPLC. A precision of $<5.0 \%$ was obtained in all cases and no significant differences were observed $(P<0.05)$.

\section{Introduction}

Dyes are a group of additives used to improve the appearance of foods, textiles, and medicine allowing the homogenizing and the assertion of the color, which is the most important sensory characteristic [1]. Synthetic dyes have been used because they are more resistant to changes in temperature and acidity [2] than natural dyes. All of these compounds contain a chromophore group and different substituents resulting in a large group of synthetic dyes, each with particular chemical properties.

The azo dyes are the most commercially used group of synthetic dyes. The main feature of these compounds is the presence of an azo group $(-\mathrm{N}=\mathrm{N}-)$ and aromatic groups, resulting in a substance with high electron conjugation and a high molar absorption coefficient, making it useful at low concentrations [3].
Tartrazine, also known as yellow 5 or E 102 dye, is one of the most important synthetic azo dyes used in the food industry to confer a yellow color to food. It is soluble in water $(14 \mathrm{mg} / 100 \mathrm{~mL})$ giving a yellow color to the solution. It is usually applied in pastries, baked goods, snacks, drinks, biscuits, ice cream, and other sweets [4].

In spite of its useful qualities, tartrazine has also been associated with allergenic effects, hyperactivity, and attention deficit disorder [5]. For this reason, the toxicity of tartrazine was studied in the early 60 s by the Expert Committee on Food Additives of FAO/WHO, which established an acceptable daily intake (ADI) of $7.5 \mathrm{mg} \mathrm{kg}^{-1}$ of body weight per day. Moreover, since 2010, foods containing tartrazine must carry the warning "may alter the activity and attention in children." In Mexico, this dye is regulated according to the Official Mexican Standard NOM-218-SSA1-2011 which 
allows $100 \mathrm{mg} \mathrm{L}^{-1}$ as the maximum amount of tartrazine in commercial beverages [6].

In general, the methodology for the quantification of dyes involves a sample treatment, identification, and quantification steps. The chosen method depends on the type of food and the lipid, protein, and carbohydrate content. Other properties such as acid-base properties of the analyte and the interferences present in the sample matrix are also important [7]. Thus, when liquid chromatography, capillary electrophoresis, and electrochemical techniques are used, it requires a simple treatment of the sample, usually dilution and subsequent filtration. However, these instrumental methods have certain disadvantages such as the high cost of analysis (equipment and reagents) and lower analysis rate (2-4 samples per hour) $[8,9]$. On the other hand, if the determination of dyes is completed using a quick and simple spectrophotometric technique, it must be considered that the presence of preservatives (sodium benzoate or citrate) and proteins may interfere significantly during the quantification step. According to this, the isolation of the sample dye using different extraction materials is critical during the analytical process [9].

Different separation strategies have been evaluated for dye extraction. Anion exchange, where acid dyes are retained by sulfonic groups present in the polymer structure [10], and liquid-liquid extraction (n-butanol-water) based on the formation of ion pairs with trimethyloctadecylammonium salts [11] have been proposed. Solid phase extraction is another technique used to isolate dye from complex matrices. The solid phases used for this purpose were zeolite or silica $\mathrm{C} 18$; the retained dye was eluted from the solid phase with methanol $[12,13]$.

Additionally, activated carbon has been proposed as colorant adsorbent because it has an excellent surface area and a well-defined pore structure that favors the retention of the analyte [14-17]. Despite its versatility, the activated carbon has the disadvantage of being difficult to separate from the aqueous matrix where it was dispersed. In order to facilitate separation of the extraction support from the liquid phase, Šafař́k ková and Šafař́k [18] propose the magnetic solid phase extraction (MSPE). MSPE is based on the use of magnetite-modified activated carbon as the solid phase with paramagnetic properties. For this reason, the support can be easily isolated from the dispersion medium by applying an external magnetic field. The main advantages of MSPE are as follows: (1) presenting the possibility of using large volumes of samples, greatly reducing the time of pretreatment and the analysis result; (2) having great interaction between analytes and the solid phase with the full dispersion of the adsorbent in the sample; and (3) providing easy isolation of the adsorbent from the analytical matrix, reducing the risk of loss of analyte [19].

In spite of their promising qualities, the MSPE has been used mainly for the separation of antibiotics and other organic molecules [20]. The use for the extraction of dyes has been limited to the determination of Reactive Red 198 [21], and methylene Blue [22]. In all cases, the main advantage of the adsorbent support was its selectivity in the extraction of the analyte and the possibility of using volumes from 100 to
$1000 \mathrm{~mL}$ [18], providing shorter analysis times as compared to conventional techniques.

According to the above-mentioned, the purpose of this work is to design a methodology based on magnetic solid phase extraction using magnetite-modified carbon for the spectrophotometric analysis of tartrazine. The method was used for the analysis of this dye in a complex matrix of nonalcoholic beverages.

\section{Materials and Methods}

2.1. Synthesis and Characterization of Magnetite-Modified Carbon. For the synthesis of the magnetite-modified carbon, a commercial activated vegetable carbon from Clarimex S.A. de C.V. was used. The synthesis was performed in two stages: in the first stage, magnetite was obtained by precipitation and its partial oxidation of iron (II) sulfate heptahydrate $\mathrm{FeSO}_{4} \cdot 7 \mathrm{H}_{2} \mathrm{O}(3.6 \mathrm{~g})$. The iron precursor was dissolved in $100 \mathrm{~mL}$ of deionized water, stirring constantly and keeping at $60^{\circ} \mathrm{C}$. The $\mathrm{pH}$ solution was adjusted to $10.0 \pm 0.2$ and a stream of air was passed through the reaction mixture. The initial green precipitate $\left(\mathrm{Fe}(\mathrm{OH})_{2} \cdot x \mathrm{H}_{2} \mathrm{O}\right)$ turned black after 40 minutes of reaction as a consequence of the partial oxidation of $\mathrm{Fe}(\mathrm{II})$ to $\mathrm{Fe}$ (III) by the action of the $\mathrm{O}_{2}$ from the air stream; the black color of the precipitate is characteristic for $\mathrm{Fe}_{3} \mathrm{O}_{4}$ [23]. In the second step, $1.0 \mathrm{~g}$ of activated carbon was added to the reaction vessel and the mixture was stirred for 30 minutes. The magnetic phase was separated with a magnet and washed three times with distilled water. The solid phase was dried at $60^{\circ} \mathrm{C}$ for $24 \mathrm{~h}$. The solid phase was pulverized in an agate mortar and stored in a desiccator until use.

In order to carry out the characterization of the synthesized magnetite-modified carbon, various instrumental techniques were used. X-ray powder diffraction analysis was performed in a Philips PW1710 instrument equipped with a copper anode and an automatic divergent opening. The conditions for the analysis were $1.54 \AA \mathrm{CuK} \alpha$ radiation; $40 \mathrm{kV}$ voltage tube; $30 \mathrm{~mA}$ current tube; 0.500 intensity ratio $(a 2 / a 1) ; 1^{\circ}$ divergence slit; 0.1 receiving slit; $\left(2 \theta^{\circ}\right) 5$ initial angle; $\left(2 \theta^{\circ}\right) 70$ end angle.

Morphological analysis of the solid was performed in a scanning electron microscopy (SEM) JEOL JSM-820. Qualitative analysis and determination of the distribution of magnetite in the solid were performed with a LINK QX2000 analyzer by Energy Dispersive X-ray Spectroscopy. All spectra were obtained at $15 \mathrm{kV}$, a distance of $39 \mathrm{~mm}$, and 2,500 counts; the detector angle relative to the sample in all cases was $45^{\circ}$.

2.2. Tartrazine Extraction-Elution. For the extraction studies, $0.05 \mathrm{~g}$ of magnetite-modified carbon was mixed with $20.0 \mathrm{~mL}$ of aqueous solution of tartrazine and stirred mechanically for 30 minutes. The $\mathrm{pH}$ value for tartrazine solution was varied using acetate $(\mathrm{pH}=5.0)$, phosphate $(\mathrm{pH}=7.0)$, and borate $(\mathrm{pH}=9.0)$ solutions at $1.0 \mathrm{~mol} \mathrm{~L}^{-1}$ concentration. After the extraction, the solid phase was separated using a neodymium magnet and the remaining liquid phase was analyzed by spectrophotometry at a wavelength of $434 \mathrm{~nm}$ 
in a UV-Vis spectrophotometer HACH DR-2700 with a quartz cell with $1.0 \mathrm{~cm}$ of path length. Thus, the remaining tartrazine was quantified by interpolation in a calibration line constructed with standard solutions of tartrazine (10.0$100.0 \mathrm{mg} \mathrm{L}^{-1}$ ) prepared in the respective buffer solution. A control experiment was carried out using activated carbon in order to evaluate the effect of the magnetic modifications in support of the tartrazine extraction.

For the elution of the retained tartrazine from the synthetized support, several eluting systems were evaluated following this procedure in triplicate: $50 \mathrm{mg}$ of solid phase containing tartrazine was mixed with $2.0 \mathrm{~mL}$ of eluent and stirred using ultrasound for 5 minutes. $2 \mathrm{~mL}$ of the resulting solution was transferred to a $10 \mathrm{~mL}$ volumetric flask and filled with eluent solution up to the mark. The eluted tartrazine was quantified by interpolation in a calibration line constructed with absorbance values of standard solutions of tartrazine $\left(10.0-100.0 \mathrm{mg} \mathrm{L}^{-1}\right)$ prepared in the respective eluent solution.

2.3. Analysis of Real Samples. Six samples of commercial beverages containing tartrazine were analyzed in triplicate following this protocol: $10 \mathrm{~mL}$ aliquot of the drink was mixed with $2.5 \mathrm{~mL}$ of $1.0 \mathrm{~mol} \mathrm{~L}^{-1}$ acetate buffer solution and transferred to a $25 \mathrm{~mL}$ volumetric flask and then deionized water was added up to the mark. Later, $20.0 \mathrm{~mL}$ of this solution was placed in a polypropylene tube containing $75 \mathrm{mg}$ of magnetic support and mechanically stirred for 30 minutes in order to extract the dye. After the extraction, the solid phase was removed from the aqueous matrix using a neodymium magnet. The solid phase was then mixed with $1.0 \mathrm{~mL}$ of eluent and stirred for 5 minutes using ultrasound to remove the extracted tartrazine. The liquid phase was transferred to a $10 \mathrm{~mL}$ volumetric flask and filled with elution solution up to the mark. The concentration of tartrazine in the last solution was determined spectrophotometrically.

In order to evaluate the proposed methodology, the amount of tartrazine in the commercial beverages was also analyzed using an HPLC. This method considers a calibration line using standard solutions of tartrazine from 5 to $20 \mathrm{~m} \mathrm{~L} \mathrm{~L}^{-1}$. Samples were prepared as follows. An aliquot of $0.5 \mathrm{~mL}$ was diluted adding a mobile phase up to $5 \mathrm{~mL}$. In order to introduce the samples to the chromatographic system, it was necessary to filter it using membranes of $0.45 \mu \mathrm{m}$ pore size.

\section{Results and Discussion}

3.1. Characterization of Modified Carbon. Instrumental techniques were used to provide information about the composition and structure of the magnetic modified carbon. Thus, the X-ray diffraction (XRD) studies were performed in order to determine the iron oxide form present in the solid. The XRD diffractograms from Figure 1(a) show the signals labeled as " $\mathrm{m}$ " that correspond to the characteristic diffraction lines of $\mathrm{Fe}_{3} \mathrm{O}_{4}\left(2 \theta=30.1^{\circ}, 35.5^{\circ}, 43.1^{\circ}, 53.4^{\circ}, 57.0^{\circ}\right.$, and $\left.62.6^{\circ}\right)$ according to the Joint Committee on Powder Diffraction Standards [24]. The broadband signal observed between $20^{\circ}$

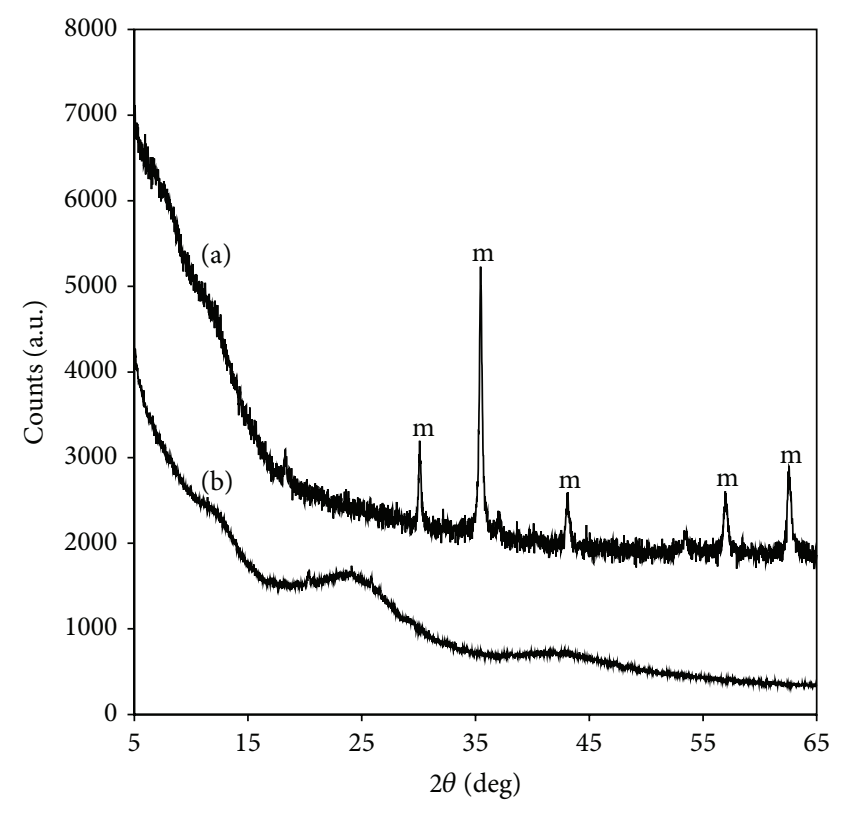

FIGURE 1: Diffractogram of (a) magnetic modified carbon support and (b) activated carbon.

and $30^{\circ}$ for the $2 \theta$ angle (Figure $1(\mathrm{~b})$ ) is characteristic of amorphous carbon, the raw material.

The morphological study with scanning electron microscopy (SEM) for activated carbon shows a uniform phase with inhomogeneous particle sizes greater than $20 \mu \mathrm{m}$ (Figure 2(a)). The micrograph is consistent with SEM studies performed without modifying the activated carbon [25]. In the case of the synthetized support, it can be seen that the activated carbon is covered by a phase with a smaller size (Figure 2(b)). This was confirmed with the energy dispersive spectrum (Figure 2(c)) that shows a larger amount of carbon for the section (I), while the Fe-content is greater for the area (II), so it is concluded that the magnetite phase is covering the activated carbon.

3.2. Study of Chemical Variables for the Extraction of Tartrazine with the Magnetic Modified Carbon Support. The extraction of tartrazine from standard solutions using the synthetized modified carbon is shown in Figure 3. It is possible to visually verify the cleaning process of the tartrazine solution.

The capability of the synthetized modified carbon for the extraction of tartrazine was also evaluated at different $\mathrm{pH}$ values. The results shown in Figure 4 correspond to acidic, basic, and neutral medium adsorption isotherms constructed by plotting the concentration of tartrazine in the solution at equilibrium $(\mu \mathrm{M})$ against the concentration of the sorbate on the solid phase $\left(\mathrm{mmol} \mathrm{kg}^{-1}\right)$ after adsorption. Additionally, Table 1 shows the maximum quantity of adsorbate on the solid support at different $\mathrm{pH}$ values.

According to Figure 4 and Table 1, the decrease of $\mathrm{pH}$ values results in the increase of the amount of absorbed tartrazine. This is consequence of the interaction of tartrazine 


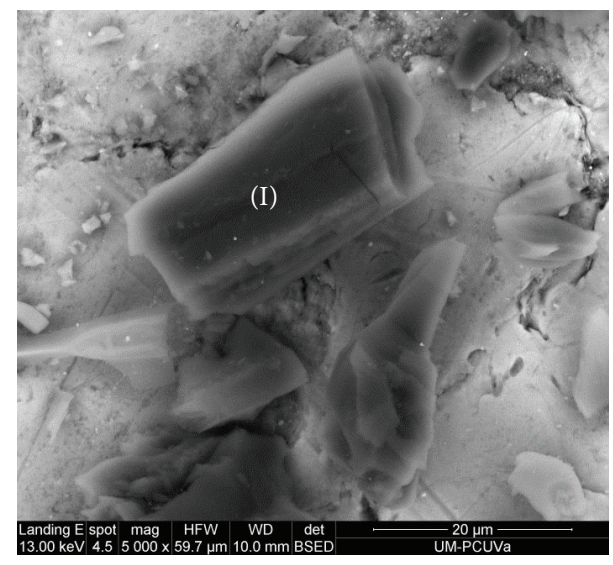

(a)

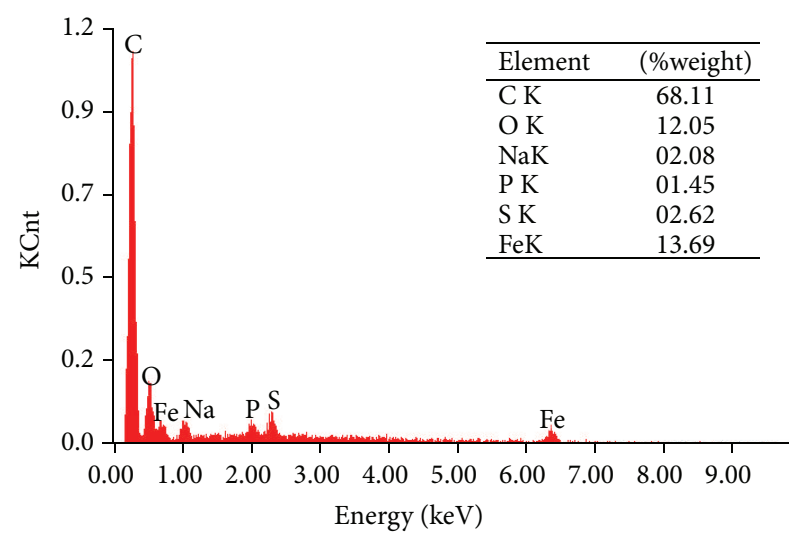

(I)

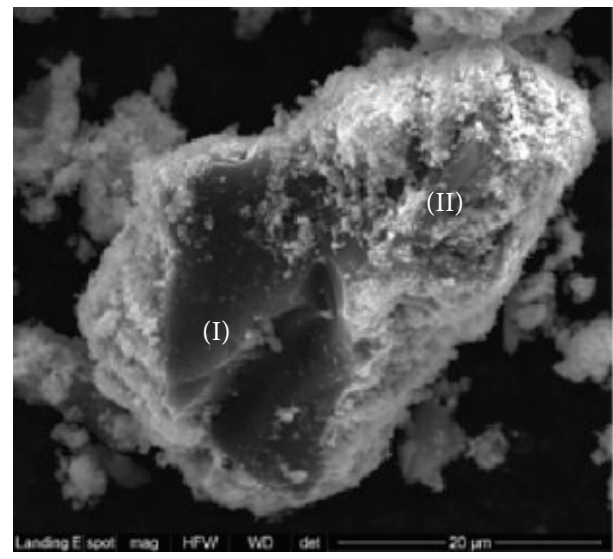

(b)

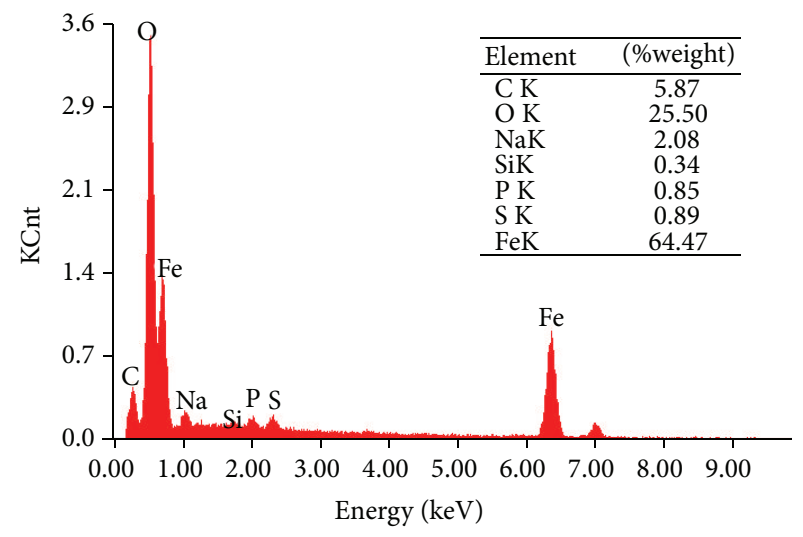

(II)

(c)

FIGURE 2: (a) Micrograph for activated carbon; (b) micrograph for magnetic modified carbon support; (c) energy dispersive spectra obtained from the analysis of zones I and II of magnetic modified carbon support.

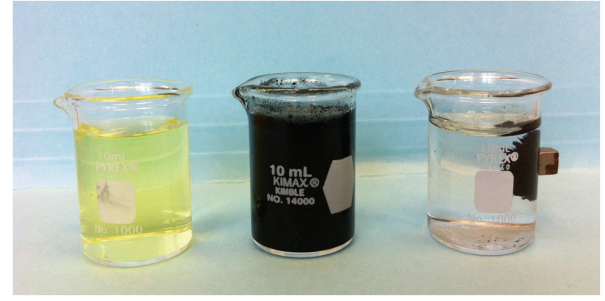

FIGURE 3: Adsorption experiment. From left to right: dissolution of tartrazine, mixture of tartrazine with magnetic modified carbon, and magnetic support separation.

TABLE 1: Maximum adsorbed tartrazine on the adsorbent at different $\mathrm{pH}$ values.

\begin{tabular}{lc}
\hline $\mathrm{pH}$ value & Tartrazine adsorbed $\left(\mathrm{mmol} \mathrm{kg}^{-1}\right)$ \\
\hline 5.0 & 54.5 \\
7.0 & 48.4 \\
9.0 & 42.7 \\
\hline
\end{tabular}

in its anionic form with the acid form of the magnetite at low $\mathrm{pH}$ values. In basic medium a repulsion between the negative charges of tartrazine in solution and the support is reflected in the reduction of the adsorbate retention [26]. Based on these results, $\mathrm{pH}$ of 5.0 was selected as the most suitable value for the retention of dye.

As part of the characterization of the MSPE-dye system, the affinity constant value between substrate and tartrazine was estimated. The analysis of the isotherm values using a Scatchard plot demonstrates the value of the affinity constant $K_{d}$ for the following dissociation reaction [27]:

$$
\mathrm{TS} \leftrightarrows \mathrm{T}+\mathrm{S},
$$

where TS corresponds to tartrazine adsorbed on the support, $\mathrm{T}$ is the tartrazine in solution, and $\mathrm{S}$ is the magnetic modified carbon support.

$\log K_{d}$ values are shown in Table 2, observing a linear trend which is associated with the homogeneity of the support. Because this is a dissociation constant, it follows that the support with a higher affinity is the activated carbon; 


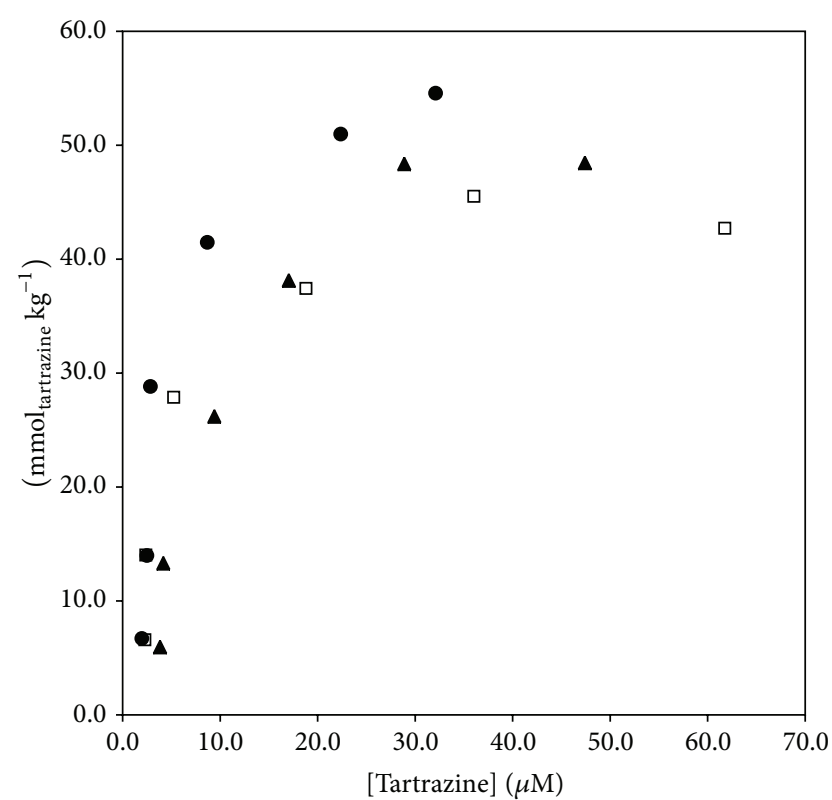

FIGURE 4: Adsorption isotherms for tartrazine on magnetic carbon modified at $\mathrm{pH}$ values $(\bullet)$ 5.0, (ム) 7.0, and () 9.0.

TABLE 2: Tartrazine magnetic-modified carbon support dissociation constants.

\begin{tabular}{lc}
\hline Support & $\log K_{d}$ \\
\hline Activated carbon & -28 \\
Magnetic-modified carbon & -6.5 \\
\hline
\end{tabular}

TABLE 3: Results of the evaluation of different systems for tartrazine elution.

\begin{tabular}{lccc}
\hline Eluent & Signal 1 & Signal 2 & Signal 3 \\
\hline Methanol & 0.6000 & 0.6010 & 0.6020 \\
Basified methanol & 0.7720 & 0.7700 & 0.7700 \\
Acetonitrile & 0.1460 & 0.1460 & 0.1450 \\
Basified acetonitrile & 0.4440 & 0.4420 & 0.4440 \\
\hline
\end{tabular}

however, the synthetized support has a suitable $\log K_{d}$ value because in the retention-elution methodologies design, it is recommended that the support has an average affinity to the substrate with $\log K_{d}$ values between -7.0 and -4.0 [20].

Additional studies on the selection of the best chemical conditions for the tartrazine elution adsorbed on the magnetic modified carbon were performed. Thus, several eluting systems were evaluated for the elution step: methanol, acetonitrile, basified methanol, and basified acetonitrile [28, 29]. After the spectrophotometric analysis of the eluted tartrazine, it can be seen that basified methanol provides the greater signal (Table 3 ) as a consequence of removing a greater amount of tartrazine. For this reason, this eluent was chosen for elution of tartrazine in the following experiments.

3.3. Optimization of the Physical Variables of the MSPE Process. To optimize the conditions for the retention and elution of tartrazine involved in the MSPE system, a Taguchi
TABLE 4: Matrix obtained during optimization design for the MSPE system.

\begin{tabular}{lccccc}
\hline Experiment & $\begin{array}{c}V_{M} \\
(\mathrm{~mL})\end{array}$ & $\begin{array}{c}V_{E} \\
(\mathrm{~mL})\end{array}$ & $\begin{array}{c}m_{\mathrm{C}} \\
(\mathrm{mg})\end{array}$ & $\begin{array}{c}C_{E} \\
(\mathrm{M})\end{array}$ & \% recovery \\
\hline 1 & 10.0 & 1.0 & 50 & 0.0025 & 6.66 \\
2 & 10.0 & 2.0 & 75 & 0.025 & 23.48 \\
3 & 10.0 & 3.0 & 100 & 0.25 & 27.74 \\
4 & 20.0 & 1.0 & 75 & 0.25 & 99.95 \\
5 & 20.0 & 2.0 & 100 & 0.0025 & 7.49 \\
6 & 20.0 & 3.0 & 50 & 0.025 & 44.10 \\
7 & 30.0 & 1.0 & 100 & 0.025 & 31.59 \\
8 & 30.0 & 2.0 & 50 & 0.25 & 90.58 \\
9 & 30.0 & 3.0 & 75 & 0.0025 & 24.19 \\
\hline
\end{tabular}

experimental design was performed. The main advantage of this technique is that it provides useful information with minimal experimentation using matrices of special design (orthogonal arrays), in which columns (factors or controllable parameters) and rows (experiments) are accommodated in such a way that a combination of factors and levels of each experiment are indicated [30].

The selected response factor was the percentage of recovery for the analysis of $20 \mathrm{~mL}$ of a solution of $30 \mathrm{mg} \mathrm{L}^{-1}$ tartrazine. The selected control factors (parameters), each at 3 levels, were sample volume, volume of eluent, mass of magnetic modified carbon support, and $\mathrm{NaOH}$ concentration in the eluent [20]. Based on an L9 (34) Taguchi orthogonal array, the matrix design and results obtained are shown in Table 4.

Figure 5 shows a typical graph obtained by plotting the average percentage of recovery for each factor against each of its levels. According to this, the most suitable conditions for tartrazine adsorption-elution were $20 \mathrm{~mL}$ sample, $1 \mathrm{~mL}$ of eluent, $75 \mathrm{mg}$ of magnetic modified carbon, and a concentration of $0.25 \mathrm{~mol} \mathrm{~L}^{-1} \mathrm{NaOH}$ for the basified methanol solution. These conditions correspond to experiment number 4 , which has the highest percentage of dye recovery.

Additionally, the contribution percentage of each variable was determined by ascertaining that $\mathrm{NaOH}$ concentration in the eluting solution has the greater effect (45.4\%), followed by the sample volume (23.6\%), the mass of adsorbent (20.4\%), and the eluent volume (10.6\%). The higher contribution of the eluting solution in the tartrazine elution step confirms the theory of charge-repulsion between support and analyte, which is favored at a higher concentration of $\mathrm{NaOH}$.

3.4. Analytical Parameters of the MSPE Developed Method. Under the optimized conditions described above, calibration lines using tartrazine standard solutions in the concentration range of 5.0 to $30.0 \mathrm{mg} \mathrm{L}^{-1}$ were carried out. The obtained signal (AU) was measured in triplicate and the calibration lines were plotted using the average signal of the eluted tartrazine. Calibration lines show a linear dependence between the average signal and the concentration of tartrazine present 


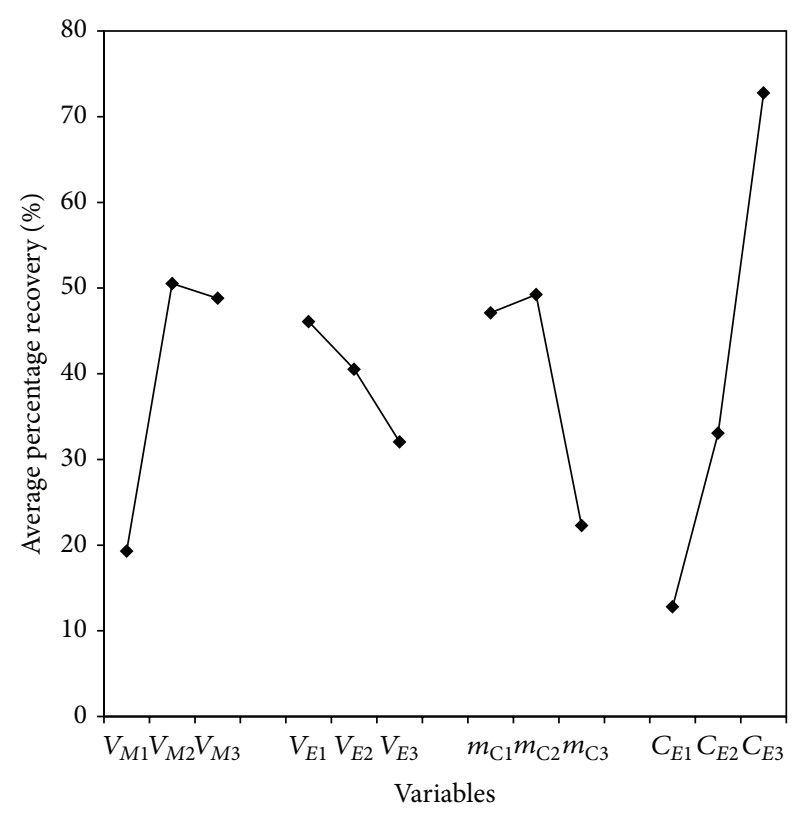

FIGURE 5: Plot of average effects in the tartrazine recovery. $V_{M}$ : sample volume; $V_{E}$ : eluent volume; $m_{C}$ : magnetic modified carbon; and $C_{E}: \mathrm{NaOH}$ concentration in the eluent.

TABLE 5: Parameters of the regression line for signal (AU) versus tartrazine concentration $\left(\mathrm{mg} \mathrm{L}^{-1}\right)$ plot.

\begin{tabular}{lc}
\hline Parameter & Value \\
\hline Root mean square deviation, $s_{e}$ & 0.013 \\
Intercept, $b_{0} \pm$ ts $\left(b_{0}\right)$ & $0.010 \pm 0.031$ \\
Slope, $b_{1} \pm$ ts $\left(b_{1}\right)$ & $0.041 \pm 0.003$ \\
Linear interval $\left(\mathrm{mg} \mathrm{L}^{-1}\right)$ & $3.0-30.0$ \\
Limit of detection $\left(\mathrm{mg} \mathrm{L}^{-1}\right)$ & 1.0 \\
Repeatability (\%RSD, $\left.n=3,10.0 \mathrm{mg} \mathrm{L}^{-1}\right)$ & 1.8 \\
Reproducibility $\left(\% \mathrm{RSD}, n=9,10.0 \mathrm{mg} \mathrm{L}^{-1}\right)$ & 3.2 \\
\hline
\end{tabular}

in the initial standard solution. Table 5 shows the calibration line regression parameters.

From the values reported in Table 5, it can be seen that the proposed methodology allows for the quantification of tartrazine in drinks at levels established by the Official Mexican Standard NOM-218-SSA1-2011 which allows $100 \mathrm{mg} \mathrm{L}^{-1}$ as the maximum amount of tartrazine in commercial beverages [5].

3.5. Interference Study. Several nonalcoholic beverages containing tartrazine also have additives as proteins and preservatives that improve physical appearance and shelf life. For this reason, the tartrazine adsorption-elution method was evaluated adding several interfering compounds. The evaluated interferents included casein, egg albumin, acesulfame $\mathrm{K}$, sodium benzoate, aspartame, sodium citrate, glucose, and sucrose. Solutions of each interfering compound were prepared dissolving $10 \mathrm{mg}$ in $10 \mathrm{~mL}$ acetate buffer.

To perform the test, $75 \mathrm{mg}$ of magnetic modified carbon was mixed with $20 \mathrm{~mL}$ of $30 \mathrm{mg} \mathrm{L}^{-1}$ tartrazine solution and $3 \mathrm{~mL}$ of interferent solution. After this absorption step, $1 \mathrm{~mL}$
TABLE 6: Chemical composition of the analyzed commercial beverages.

\begin{tabular}{|c|c|}
\hline Sample & Composition \\
\hline 1 & $\begin{array}{l}\text { Soy (water and selected soy seeds), sugar, } \\
\text { maltodextrin, concentrated pineapple juice, flavor } \\
\text { identical to natural, pectin, and tartrazine. }\end{array}$ \\
\hline 2 & $\begin{array}{l}\text { Water, sugar, concentrated orange, tartrazine, and } \\
\text { sodium. }\end{array}$ \\
\hline 3 & $\begin{array}{l}\text { Water, corn syrup, high fructose, concentrated } \\
\text { pineapple juice reconstituted, citric acid, pectin, } \\
\text { artificial flavor, acesulfame K, and yellow } 5 \text {. }\end{array}$ \\
\hline 4 & $\begin{array}{l}\text { Water, high fructose corn syrup, sugar, citric acid, } \\
\text { sodium chloride, sodium citrate, monosodium } \\
\text { phosphate, Arabic gum, ester gum, natural } \\
\text { lemon-lime flavor, and tartrazine. }\end{array}$ \\
\hline 5 & $\begin{array}{l}\text { Water, high fructose corn syrup, concentrated juice } \\
\text { ( } 7 \% \text { orange and } 3 \% \text { pineapple), citric acid, ascorbic } \\
\text { acid, acacia gum, ester gum, natural and artificial } \\
\text { flavors, sodium citrate, yellow } 5 \text { (tartrazine), and } \\
\text { beta carotene dyes. }\end{array}$ \\
\hline
\end{tabular}

TABle 7: Contents of tartrazine (mean and \%RSD, $n=3$ ) in real samples determined with the proposed methodology and comparison with HPLC reference method.

\begin{tabular}{lcc}
\hline Sample & \multicolumn{2}{c}{ [Tartrazine] $\left(\mathrm{mg} \mathrm{L}^{-1}\right)$} \\
\hline 1 & MSPE-UV & HPLC \\
2 & $5.5(1.3)$ & 5.4 \\
3 & $22.7(0.8)$ & 22.4 \\
4 & $5.9(1.8)$ & 5.7 \\
5 & $22.8(2.3)$ & 23.0 \\
\hline
\end{tabular}

of basified methanol with $\mathrm{NaOH} 0.25 \mathrm{~mol} \mathrm{~L}^{-1}$ was used to elute tartrazine. Then $0.5 \mathrm{~mL}$ of the eluted solution was transferred to a $5 \mathrm{~mL}$ volumetric flask and filled up to the mark. This solution was analyzed by UV-Vis spectrophotometry. Results did not show a \%RSD value higher than $5 \%$ of the analytical signal in a similar experiment without interferents. According to this, the proposed compounds do not interfere with the tartrazine determination following the proposed methodology.

3.6. Analysis of Real Samples. The tartrazine concentration in six commercially available beverages was determined. The main components of every beverage that were reported by the manufacturer are listed in Table 6.

Following the developed and optimized method, the tartrazine concentration for each beverage is shown in Table 7. This value represents the average of three independent determinations. Additionally, in Table 7 it is possible to observe the results for the analysis of samples using the HPLC reference method and MSPE-HPLC (Figure 6). For each beverage, the average concentration of tartrazine obtained using both methods was compared using a $t$-test with 2 degrees of freedom and $95 \%$ of confidence $\left(t_{\mathrm{tab}}=4.3\right)$. This analysis revealed no significant differences between the results from 


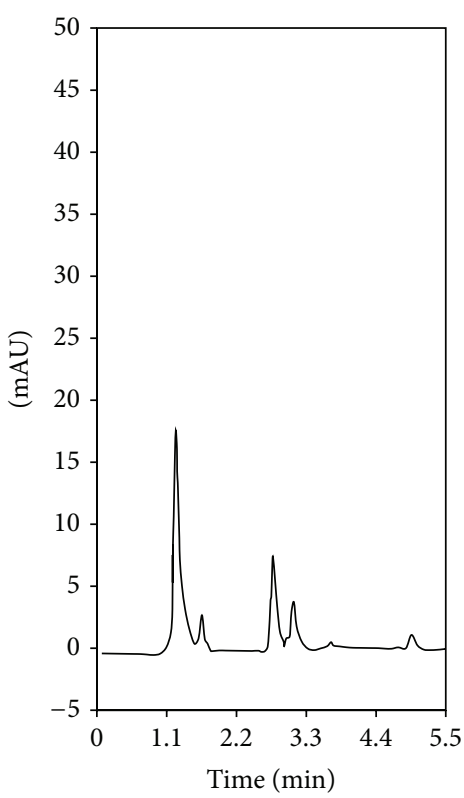

(a)

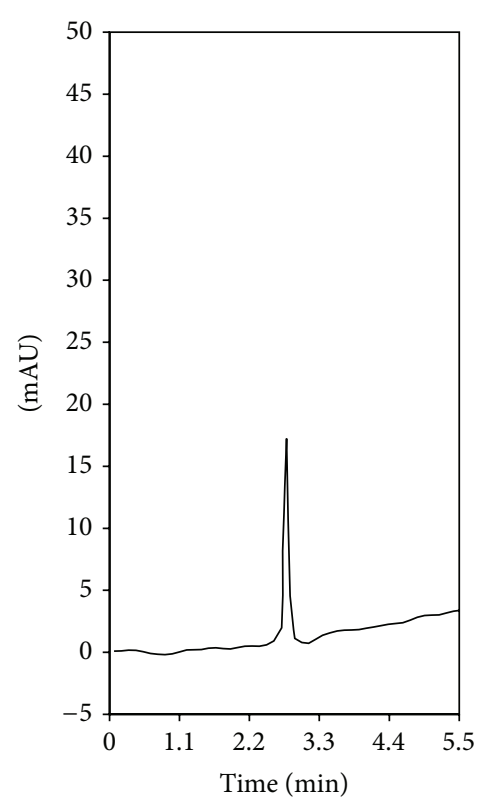

(b)

FIGURE 6: Chromatograms of (a) original sample and (b) eluted tartrazine solution after using MSPE developed method.

each method. Therefore, the methodology of MSPE is comparable with the reference methodology. Additionally, the MSPE is a robust preconcentration technique that can be coupled even to spectrophotometry or HPLC.

\section{Conclusions}

In the present work, an activated carbon covered with magnetite support was synthesized; this support has magnetic properties that allow its separation by applying an external magnetic field.

The best conditions for the extraction and elution of tartrazine were an initial sample volume of $20 \mathrm{~mL}$, buffered with acetate buffer solution, at $\mathrm{pH} 5$, and mixed with $75 \mathrm{mg}$ of magnetic modified carbon, tartrazine elution with $1 \mathrm{~mL}$ of $\mathrm{NaOH} 0.25 \mathrm{~mol} \mathrm{~L}^{-1}$ in methanol.

Thus, the proposed sample treatment coupled to spectrophotometric analysis is an alternative to the analysis of azo dyes in the food industry because the parameters, analytical precision, and accuracy are similar to HPLC methodologies. However, the proposed methodology saves time and is less expensive than the reference method.

\section{Conflict of Interests}

The authors declare that there is no conflict of interests regarding the publication of this paper.

\section{Acknowledgments}

The authors wish to thank CONACyT (Project INFR-2014227999) and Consejería de Cultura, Educación e Ordenacion Universitaria, and Xunta de Galicia (Project EM 2012/153) for the financial support. Alfredo Guevara-Lara, Ma. Elena PáezHernández, and José A. Rodríguez gratefully thank the SNI for the distinction of their membership.

\section{References}

[1] J. Abbey, B. Fields, M. O’Mullane, and L. D. Tomaska, "Food additives: colorants," in Encyclopedia of Food Safety, Elsevier, New York, NY, USA, 2014.

[2] K. Venkataraman, The Chemistry of Synthetic Dyes, vol. 4, Academic Press, New York, NY, USA, 1971.

[3] N. Sekar, "Acid dyes," in Handbook of Textile and Industrial Dyeing, Elsevier, New York, NY, USA, 2011.

[4] A. L. Branen, P. M. Davidson, S. Salminen, and J. Thorngat, Food Additives, Marcel Dekker, New York, NY, USA, 2nd edition, 2002.

[5] L. E. Arnold, N. Lofthouse, and E. Hurt, "Artificial food colors and attention-deficit/hyperactivity symptoms: conclusions to dye for," Neurotherapeutics, vol. 9, no. 3, pp. 599-609, 2012.

[6] NORMA Oficial Mexicana NOM-218-SSA1-2011, "Productos y servicios. Bebidas saborizadas no alcohólicas, sus congelados, productos concentrados para prepararlas y bebidas adicionadas con cafeína. Especificaciones y disposiciones sanitarias. Métodos de prueba," Diario Oficial de la Federación, 2012, http:// www.dof.gob.mx/nota_detalle.php? codigo $=5233379 \&$ fecha $=10 /$ 02/2012.

[7] E. C. Vidotti, W. F. Costa, and C. C. Oliveira, "Development of a green chromatographic method for determination of colorants in food samples," Talanta, vol. 68, no. 3, pp. 516-521, 2006.

[8] H.-Y. Huang, Y.-C. Shih, and Y.-C. Chen, "Determining eight colorants in milk beverages by capillary electrophoresis," Journal of Chromatography A, vol. 959, no. 1-2, pp. 317-325, 2002.

[9] N. Yoshioka and K. Ichihashi, "Determination of 40 synthetic food colors in drinks and candies by high-performance liquid 
chromatography using a short column with photodiode array detection," Talanta, vol. 74, no. 5, pp. 1408-1413, 2008.

[10] M. Wawrzkiewicz and Z. Hubicki, "Removal of tartrazine from aqueous solutions by strongly basic polystyrene anion exchange resins," Journal of Hazardous Materials, vol. 164, no. 2-3, pp. 502-509, 2009.

[11] O.-W. Lau, M. M. K. Poon, S.-C. Mok, F. M. Y. Wong, and S.F. Luk, "Spectrophotometric determination of single synthetic food colour in soft drinks using ion-pair formation and extraction," International Journal of Food Science \& Technology, vol. 30, no. 6, pp. 793-798, 2007.

[12] Y. S. Al-Degs, M. I. El-Barghouthi, A. H. El-Sheikh, and G. M. Walker, "Effect of solution $\mathrm{pH}$, ionic strength, and temperature on adsorption behavior of reactive dyes on activated carbon," Dyes and Pigments, vol. 77, no. 1, pp. 16-23, 2008.

[13] S. Şahin, C. Demir, and Ş. Güçer, "Simultaneous UV-vis spectrophotometric determination of disperse dyes in textile wastewater by partial least squares and principal component regression," Dyes and Pigments, vol. 73, no. 3, pp. 368-376, 2007.

[14] D. Xin-hui, C. Srinivasakannan, and L. Jin-sheng, "Process optimization of thermal regeneration of spent coal based activated carbon using steam and application to methylene blue dye adsorption," Journal of the Taiwan Institute of Chemical Engineers, vol. 45, no. 4, pp. 1618-1627, 2013.

[15] P. Rodríguez-Estupiñan, L. Giraldo, and J. C. Moreno-Piraján, "Energetic changes in the surface of activated carbons and relationship with $\mathrm{Ni}(\mathrm{II})$ adsorption from aqueous solution," Applied Surface Science, vol. 286, pp. 351-357, 2013.

[16] C. Zeng, Q. Lin, C. Fang, D. Xu, and Z. Ma, "Preparation and characterization of high surface area activated carbons from co-pyrolysis product of coal-tar pitch and rosin," Journal of Analytical and Applied Pyrolysis, vol. 104, pp. 372-377, 2013.

[17] H. Duygu Ozsoy and J. Van Leeuwen, "Removal of color from fruit candy waste by activated carbon adsorption," Journal of Food Engineering, vol. 101, no. 1, pp. 106-112, 2010.

[18] M. Šafaříková and I. Šafařík, "Magnetic solid-phase extraction," Journal of Magnetism and Magnetic Materials, vol. 194, no. 1-3, pp. 108-112, 1999.

[19] K. Aguilar-Arteaga, J. A. Rodríguez, and E. Barrado, "Magnetic solids in analytical chemistry: a review," Analytica Chimica Acta, vol. 674, no. 2, pp. 157-165, 2010.

[20] I. S. Ibarra, J. A. Rodriguez, J. M. Miranda, M. Vega, and E. Barrado, "Magnetic solid phase extraction based on phenyl silica adsorbent for the determination of tetracyclines in milk samples by capillary electrophoresis," Journal of Chromatography A, vol. 1218, no. 16, pp. 2196-2202, 2011.

[21] M. Janus, E. Kusiak, J. Choina, J. Ziebro, and A. W. Morawski, "Enhanced adsorption of two azo dyes produced by carbon modification of $\mathrm{TiO}_{2}$," Desalination, vol. 249, no. 1, pp. 359-363, 2009.

[22] R. Liu, X. Shen, X. Yang, Q. Wang, and F. Yang, "Adsorption characteristics of methyl blue onto magnetic $\mathrm{Ni}_{0.5} \mathrm{Zn}_{0.5} \mathrm{Fe}_{2} \mathrm{O}_{4}$ nanoparticles prepared by the rapid combustion process," Journal of Nanoparticle Research, vol. 15, no. 6, article 1679, 2013.

[23] E. Barrado, F. Prieto, M. Vega, and F. Fernández-Polanco, "Optimization of the operational variables of a medium-scale reactor for metal-containing wastewater purification by ferrite formation," Water Research, vol. 32, no. 10, pp. 3055-3061, 1998.

[24] M. C. Morris, H. F. McMurdie, E. H. Evans et al., Standard XRay Diffraction Powder Patterns, National Bureau of Standards, Washington, DC, USA, 1981.
[25] J. Zhang, X. Qiang, L. Juan, M. Yang, and Y. Xing, "Role of $\mathrm{Ni}\left(\mathrm{NO}_{3}\right)_{2}$ in the preparation of a magnetic coal-based activated carbon," Mining Science and Technology, vol. 21, no. 4, pp. 599603, 2009.

[26] Z.-X. Sun, F.-W. Su, W. Forsling, and P.-O. Samskog, "Surface characteristics of magnetite in aqueous suspension," Journal of Colloid and Interface Science, vol. 197, no. 1, pp. 151-159, 1998.

[27] A. P. Davenport, Receptor Binding Techniques, Humana Press, Totowa, NJ, USA, 2nd edition, 2005.

[28] A. Mittal, J. Mittal, and L. Kurup, "Adsorption isotherms, kinetics and column operations for the removal of hazardous dye, Tartrazine from aqueous solutions using waste materialsBottom Ash and De-Oiled Soya, as adsorbents," Journal of Hazardous Materials, vol. 136, no. 3, pp. 567-578, 2006.

[29] T. Tuzimski and A. Woźniak, "Application of solid-phase extraction and planar chromatography with diode-array detection to the qualitative and quantitative analysis of dyes in beverages," Journal of Planar Chromatography-Modern TLC, vol. 21, no. 2, pp. 89-96, 2008.

[30] R. K. Roy, Design of Experiments Using the Taguchi Approach, John Wiley \& Sons, Toronto, Canada, 2001. 

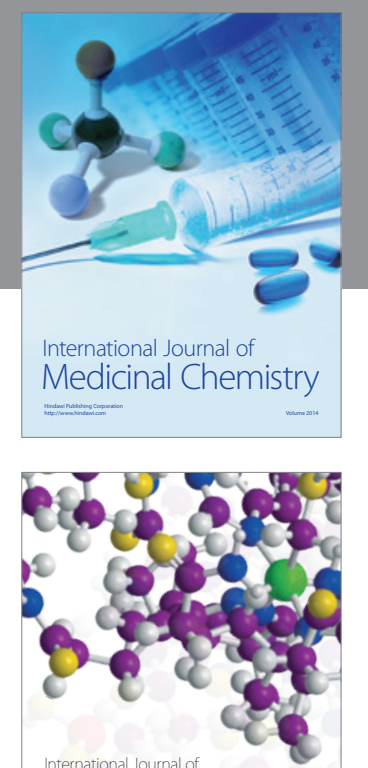

\section{Carbohydrate} Chemistry

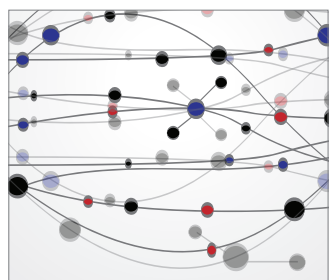

The Scientific World Journal
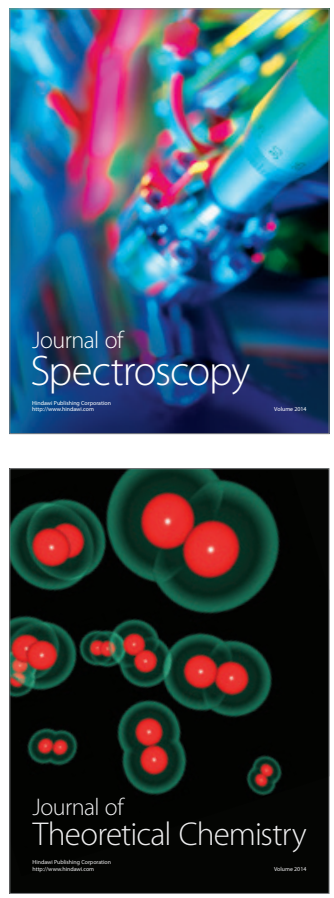
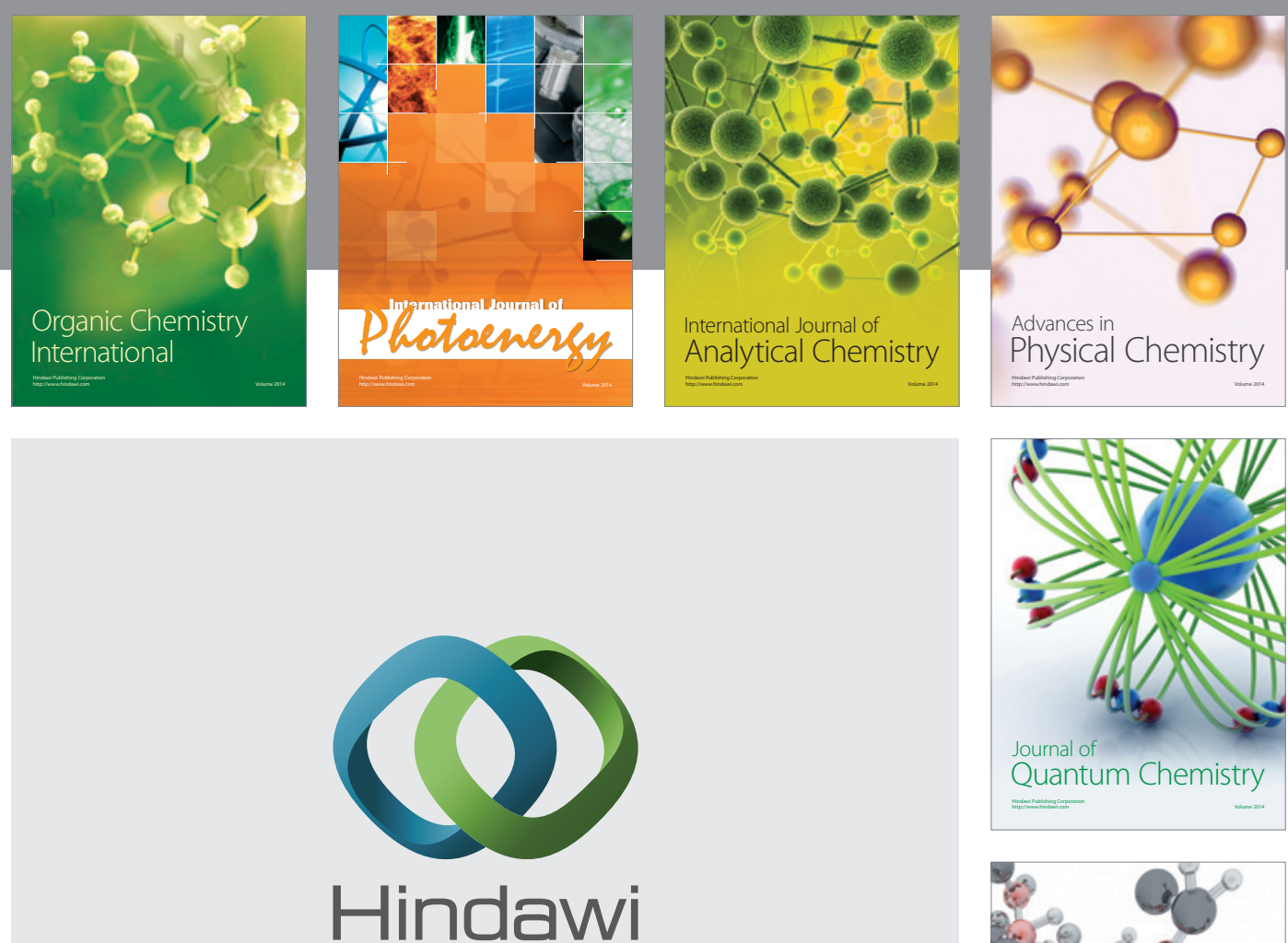

Submit your manuscripts at

http://www.hindawi.com

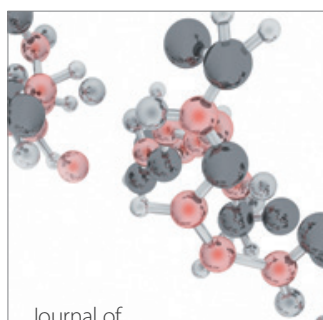

Analytical Methods

in Chemistry

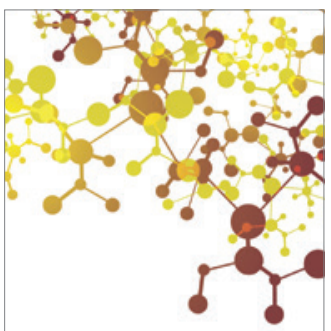

Journal of

Applied Chemistry

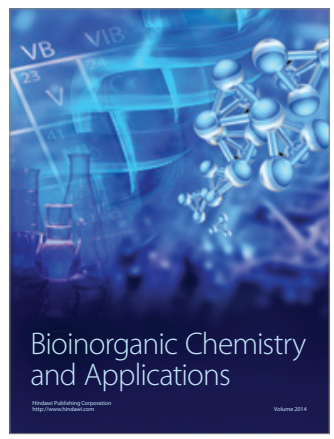

Inorganic Chemistry
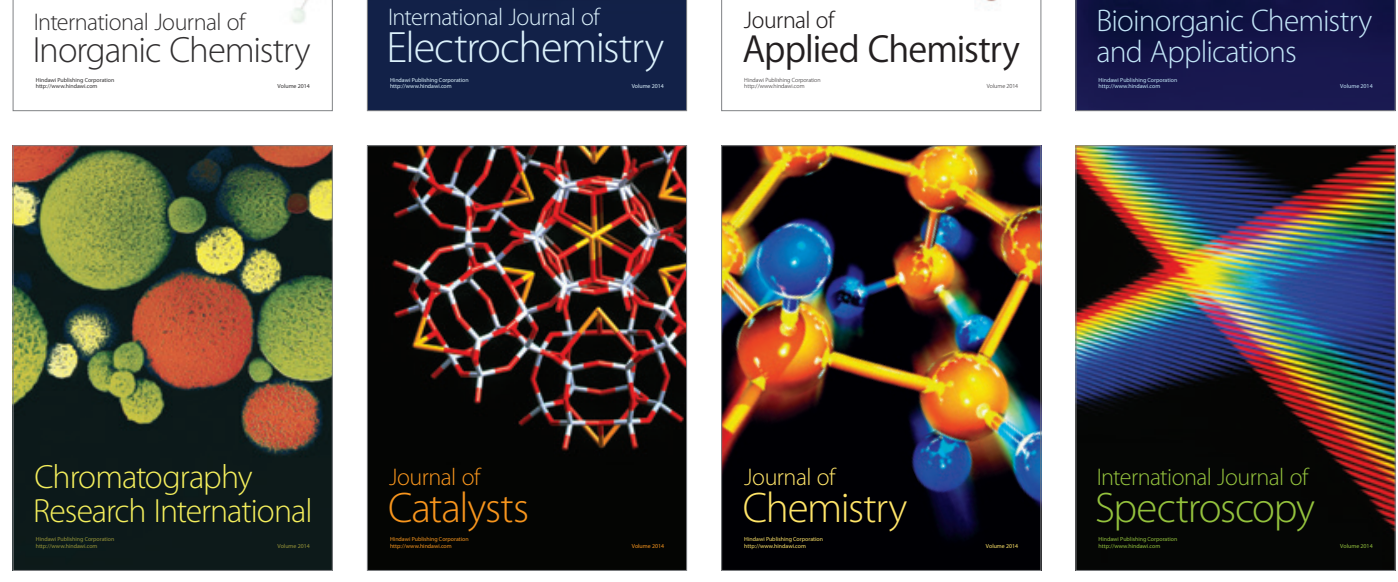